\title{
The effects of repression-sensitization classification and stress on eyewitness recall
}

\author{
ANDREA R. POLANS \\ Brooklyn College, City University of New York, Brooklyn, New York
}

(Robert Buckhout, sponsor)

\begin{abstract}
Groups of eyewitnesses to a mock crime were evaluated with Byrne's Repression-Sensitization Scale and exposed to an episode that was neutral or stressful. In testing for recall of the perpetrator's features, repressors and sensitizers did not differ in the control condition, but sensitizers showed recall significantly superior to that shown by repressors under stress conditions. Repressors nonetheless indicated higher confidence in their memory as eyewitnesses. The data support Byrne's (1964) model of cognitive avoiding and cognitive approaching response styles.
\end{abstract}

The potential for psychological theory to predict the accuracy of eyewitness testimony has been under consideration for many years (Munsterberg, 1908). Munsterberg proposed that psychologists construct objective tests to assess an individual's capacity to give testimony that reflects accurate recollection of an event. Current research has reiterated Munsterberg's position that experimental psychology can provide information about the eyewitness process. Ellison and Buckhout (1981) suggested one area of potential error in eyewitness behavior, an area stemming from characteristics of the observer. The limited research that has focused on personality dimensions and memory for faces suggests the presence of individual differences in person recognition (Clifford \& Bull, 1978). The finding that personality variables such as field dependence (Messick \& Damarin, 1964; Witkin \& Goodenough, 1977), need for approval (Schill, 1966), and need for affiliation (Atkinson \& Walker, 1956) differentially affect an individual's recognition of faces indicates that personality differences are related to memory for people.

Repression-sensitization (R-S) is a dimension of personality conceptualized by Byrne $(1961,1964)$. It refers to an individual's characteristic learned response to threatening or anxiety-arousing stimuli. Byrne hypothesized that individuals may be rated on a continuum reflecting their typical mode of dealing with threatening stimuli in their environment. At one end of the continuum are "repressors,"' who attempt to deny or minimize perceived threat, do not verbalize feelings of anxiety, and avoid thinking about the consequences of threat. At the other end of the continuum are "sensitizers," who use cognitive-approaching defense mechanisms, such as obsessive rumination, isolation of affect, and intellectualization. Sensitizers freely verbalize feelings of anxiety and

The author's mailing address is: Center for Responsive Psychology, Brooklyn College, City University of New York, Brooklyn, NY 11210. remain actively attuned to the presence of threatening stimuli. Between these two extremes are "intermediates," who do not rely excessively on cognitive-avoiding or cognitive-approaching defenses.

Traditional laboratory studies typically have yielded recognition scores approaching perfect recognition (Hochberg \& Galper, 1967; Yin, 1969) and therefore have not adequately evaluated the effects of stress on facial recognition. However, the extraordinarily high levels of laboratory performance have not been observed in real-life situations (Clifford \& Bull, 1978). The general finding has been that higher arousal leads to decreased performance on the part of eyewitnesses (Clifford \& Scott, 1978; Kuehn, 1974). The "simulated event" developed by Buckhout (1974) best approximates real life and suggests that such factors as unexpectedness, brevity of exposure, and stress are necessary factors for understanding and evaluating eyewitness behavior (Clifford \& Bull, 1978).

Previous research has suggested that there is a lack of relationship between subjects' feelings of confidence in the accuracy of their testimony and objectively assessed accuracy (Buckhout, 1974; Clifford \& Scott, 1978; Loftus, 1979). Subjects may be quite confident in their reports and yet be highly inaccurate as eyewitnesses. Personality factors in subjects' expressed confidence have not been explored to date.

The present experiment sought to examine how the characteristic cognitive-approaching and cognitiveavoiding responses of individuals classified as sensitizers and repressors differentially affected their abilities as eyewitnesses under anxiety-arousing and nonthreatening conditions. These differences were examined in terms of recall for witnessed events and of confidence in one's testimony. Specifically, it was hypothesized that under stressful conditions, sensitizers (who cognitively approach threatening stimuli) would be better eyewitnesses than repressors as measured by recall of details of the witnessed event. No R-S differences in recall and person recogni- 
tion were predicted for witnessing that occurred under nonthreatening circumstances, since there would be no need for cognitive defenses to be called into play. It was further predicted that, across experimental conditions, repressors would be significantly more confident than sensitizers in their abilities as eyewitnesses, despite the fact that they would not, in actuality, be better eyewitnesses. Previous findings have shown a discrepancy between repressors' and sensitizers' self-reported feelings and objective behavioral manifestations (Lazarus \& Alfert, 1964; Lomont, 1965; Scarpetti, 1973). In other words, the way in which repressors and sensitizers describe their feelings is often at variance with their actual behavior: Repressors tend to report themselves in more positive terms, and sensitizers tend to report themselves in more negative terms, in contrast to their actual behavior.

\section{METHOD}

\begin{abstract}
Design
The experiment was a $2 \times 3$ (treatment $\times$ levels) design with repeated measures on one variable. Repressors, intermediates, and sensitizers comprised the three levels of the classification variable. The two treatment conditions were low and high stress content of the eyewitness situation.
\end{abstract}

\section{Subjects}

The subjects were 120 male and female undergraduates. The subjects were classified on the basis of their scores on the revised Byrne R-S scale. Gamzon's (1976) norms for college students were used to determine extreme sensitizers and repressors. Those subjects scoring one standard deviation or more above or below the mean were classified as sensitizers or repressors, respectively. Those subjects whose scores fell between one standard deviation above and below the mean were classified as intermediates. Twenty subjects from each of the three R-S categories were selected randomly from the total subject pool $(\mathrm{N}=347)$ for each of the two treatment conditions.

\section{Materials}

The Byrne, Barry, and Nelson (1963) revised R-S scale was given to all subjects. The State-Trait Anxiety Inventory (STAI) State scale, developed by Spielberger, Gorsuch, and Lushene (1970), was used as a self-report measure of anxiety. Several questionnaires constructed for the experiment were administered to measure the subjects' recall and confidence level.

\section{Procedure}

All subjects completed the revised R-S scale as a group in the classroom several weeks prior to the experimental manipulation. The subjects were exposed to one of two treatment conditions, a minimally or moderately stressful eyewitness situation.

In the low-stress condition, subjects attending ongoing undergraduate courses witnessed what they believed to be a "real event." A "student" confederate entered their classroom and politely asked permission of the instructor (who had been advised of the experiment) to look for a book believed to have been left behind during a previous class. He searched the room without finding the book, apologized for interrupting, and quietly left. The subjects in the high-stress condition witnessed a similar scenario, but with the following important difference. The "student"' became very angry at not finding his book and behaved in a loud and threatening manner. In order to maximize the subjects' attention to the experimental manipulation, the "student's" entrance in both conditions was timed to interrupt a neutral presentation by the instructor at the identical point in the lecture. After the confederate had exited, the experimenter entered the classroom and informed the sub- jects that what they had just witnessed was part of a study on eyewitness behvior. No students were required to participate further, although none declined.

The subjects completed several questionnaires, including the Spielberger STAI State form as a measure of their present level of anxiety. The subjects then answered a recall questionnaire consisting of 30 forcedchoice questions designed to assess how much they remembered about what they had just witnessed. The questions pertained to the "student's" physical characteristics, clothing, verbalizations, and actions. The subjects then indicated on a 7-point Likert-type scale how confident they were in their ability to accurately recall what they had witnessed. They were also asked questions pertaining to the stressfulness and believability of the witnessed event. A planned manipulation involving the showing of a photo lineup was eliminated due to mistakes in procedure.

\section{RESULTS}

\section{Manipulation Check}

The subjects in the high-stress condition expressed significantly more anxiety than those in the low-stress condition on two self-report measures of anxiety; high-stress subjects obtained significantly higher STAI-State scores $[\mathrm{t}(118)=2.20, \mathrm{p}<.025]$ and reported significantly more stress $[\mathrm{t}(118)=8.47, \mathrm{p}<.0005]$ than low-stress subjects.

\section{Repressors vs. Sensitizers}

Overall, repressors and sensitizers differed significantly in their eyewitness behavior on measures of recall and confidence in their performance. A two-way ANOVA was used to compare repressors and sensitizers as eyewitnesses in terms of their recall ability under high and low stress. Recall scores were computed by summing the total number of correct responses on the recall questionnaire (maximum score possible $=30$ ). A significant main effect of R-S was obtained, indicating that, overall, sensitizers (mean $=20.85$ ) performed significantly better than repressors $($ mean $=19.56)$ on the recall task $[F(2,114)=4.57$, $\mathrm{p}<.05]$. A significant main effect for level of stress was also obtained. A Scheffe's test performed on the data revealed that, although repressors and sensitizers did not differ significantly in their recall ability under low stress $[F(5,115)=.42, \mathrm{p}>.05]$, sensitizers $($ mean $=22.10)$ accurately remembered significantly more details than did repressors $($ mean $=19.15)$ under high stress $[F(5,115)=$ $20.61, p<.01]$. Further Scheffé tests showed that sensitizers' recall scores were also significantly greater in the high-stress condition than were the scores obtained by sensitizers in the low-stress condition $[\mathrm{F}(5,115)=14.82, \mathrm{p}<.05]$. Repressors under high stress had slightly lower recall scores than did repressors under low stress, but the difference was not significant $[F(5,115)=1.72, p<.05]$. Post hoc analyses of intermediates' scores were performed. An inspection of Figure 1 indicates that under high- and low-stress conditions, intermediates' scores fell between those of repressors and sensitizers.

Two-way ANOVAS compared repressors' and sensitizers' confidence scores and produced a significant main effect for R-S classification. On the recall task, repres- 


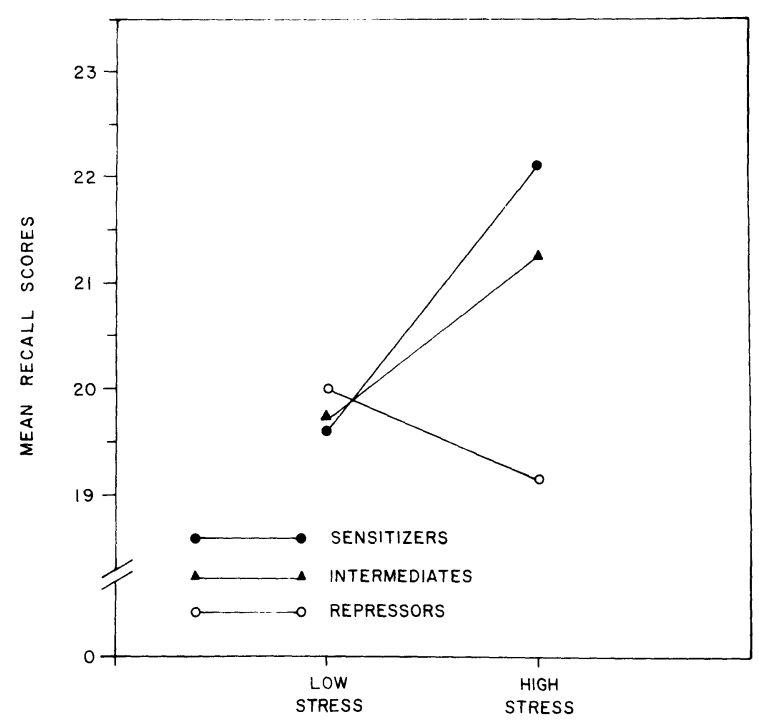

Figure 1. Mean recall scores of sensitizers, intermediates, and repressors in the low- and high-stress conditions.

sors' confidence scores (mean $=5.28$ ) were significantly higher than sensitizers' (mean $=4.35)[F(5,114)=5.80$, $\mathrm{p}<.05]$. Despite the fact that repressors did not perform significantly better than sensitizers on the recall task, they expressed significantly more confidence than sensitizers in the accuracy of their eyewitness reports.

\section{DISCUSSION}

The central findings of the present study add to the construct validity of Byrne's $(1961,1964)$ conceptualization of the R-S dimension as cognitive-avoiding versus cognitive-approaching response styles. Under low stress, when there was no need for defensive styles to be called into play because anxiety was at a minimum, there was no significant difference between repressors and sensitizers in their ability to accurately remember what they had witnessed. Both groups exhibited comparable behavior as eyewitnesses-details were recalled with approximately $67 \%$ accuracy. However, the picture changed dramatically when the eyewitness situation was stressful for the observers. Witnessing that occurred under stressful circumstances produced significantly superior recall for sensitizers and nonsignificantly poorer recall for repressors. An alternative explanation for the interaction between R-S and level of stress suggests that repressors may have performed more poorly than sensitizers because they were made more anxious by the manipulation. The YerkesDodson (1908) law states that strong motivational states such as stress or other emotional arousal facilitate learning and performance up to a point, after which there is a decrement. The manipulation may have placed repressors at a point in the Yerkes-Dodson curve where stress inhibited their performance. Although both groups exhibited the same degree of anxiety in the high-stress condition, this is not conclusive evidence that repressors and sensitizers were in fact equally anxious. Studies by Hare (1966) and Scarpetti (1973) have shown that, despite sensitizers' indicating that they were more anxious than repressors on a measure of verbalized anxiety, on the physiological level, repressors showed greater galvanomic skin response (GSR) reactivity and took longer to extinguish these reactions once the threatening conditions were removed than did sensitizers.

The prediction that there would not be a direct relationship between level of confidence and level of performance for repressors and sensitizers was confirmed. Despite the fact that repressors have significantly more confidence than sensitizers in their ability as eyewitnesses, they do not in actuality make better eyewitnesses. To the contrary, they are less able to remember details of what they have seen when the initial eyewitnessing takes place under moderately stressful circumstances. Sensitizers express more doubts about themselves, but, when put to the test, are better eyewitnesses on the whole. These findings support the conclusions drawn by other researchers that there is a lack of relationship between subjects' feelings of confidence of correctness and objectively assessed accuracy (Buckhout, 1974; Clifford \& Scott, 1978; Loftus, 1979).

The present findings have important implications for the further study of personality variables in evaluating eyewitness testimony. The United States legal system relies heavily on the testimony of eyewitnesses as a form of "direct" evidence. The individual who has witnessed a crime has been described by some jurists to operate much like a tape recorder or camera; that is, he or she is assumed to possess "the facts" recorded in perfect and complete detail. Not only is eyewitness behavior fallible, but the present study also suggests that personality variables may affect one's accuracy as an eyewitness as well as one's belief in the correctness of one's reported observations.

There is a paucity of research investigating the role that stress plays in affecting eyewitness testimony. The general finding has been that the emotionality surrounding an event affects both completeness and accuracy of eyewitness reports, with higher arousal leading to decreased performance (Clifford \& Scott, 1978; Kuehn, 1974). The present experiment suggests that this is not a simple relationship and that personality factors interact with situational factors to affect eyewitness testimony. Research on these interactive effects is clearly warranted.

\section{REFERENCES}

Atkinson, J. W., \& Walker, E. L. (1956). The affiliation motive and perceptual sensitivity to faces. Journal of Abnormal and Social Personality, 53, 38-41.

BuckнouT R. (1974). Eyewitness testimony. Scientific American, 231(6), 23-31.

Buckhout, R., Alper, A., Chern, S., Silverberg, G., \& Slomovits, M. (1974). Determinants of eyewitness performance on a lineup. Bulletin of the Psychonomic Society, 4, 191-192.

Buckhout, R., FigueroA, D., \& HoFf, R. (1975). Eyewitness identification: Effects of suggestion and bias in identification from photographs. Bulletin of the Psychonomic Society, 6, 71-74.

BYRNE, D. (1961). The repression-sensitization scale: Rationale, reliability, and validity. Journal of Personality, 29, 334-349.

BYRNE, D. (1964). Repression-sensitization as a dimension of personality. In B. Mayer (Ed.), Progress in experimental research (Vol. 1), New York: Academic Press.

Byrne, D., Barry, J., \& NELSON, D. (1963). Relation of the revised repression-sensitization scale to measures of self-description. Psychological Reports, 13, 323-334.

Clifford, B. R., \& Bull, R. (1978). The psychology of person identification. Boston: Routledge \& Kegan Paul.

Clifford, B. R., \& ScotT, J. (1978). Individual and situational factors in eyewitness testimony. Journal of Applied Psychology, 63, 352-359.

Ellison, K. W., \& Buckhout, R. (1981). Psychology and criminal justice. New York: Harper \& Row.

GAMzon, R. (1976). Conditioning of choice, of violent and neutral words as a function of repression-sensitization. Unpublished doctoral dissertation, Long Island University, Brooklyn NY.

HARE, R. D. (1966). Denial of threat and emotional response to impending painful stimulation. Journal of Consulting Psychology, 30, 359-361.

HochBerg, J., \& GALPER, R. (1967). Recognition of faces: An exploratory study. Psychonomic Science, 12, 619-620. 
Johnson, C., \& ScotT, B. (1976). Eyewitness testimony and suspect identification as a result of arousal, sex of the witness, and scheduling of interrogation. Paper presented at the meeting of the American Psychological Association, Washington, DC.

KueHN, L. L. (1974). Looking down the gun barrel: Person perception and violent crime. Perceptual and Motor Skills, 39, 1159-1164.

LaZarus, R. S., \& Alfert, E. (1964). Short-circuiting of threat by experimentally altering cognitive appraisal. Journal of Abnormal and Social Psychology, 69, 195-205.

LofTUs, E. (1979). Eyewitness testimony. Cambridge, MA: Harvard University Press.

Lomont, J. F. (1965). The repression-sensitization dimension in relation to anxiety responses. Journal of Consulting Psychology, 29, 84-86.

Messick, S., \& Damarin, F. (1964). Cognitive style and memory for faces. Journal of Abnormal and Social Psychology, 69, 313-318.

MunsterberG, H. (1908). On the witness stand: Essays on psychology and crime. New York: Doubleday Page.

SCARPETTI, W. L. (1973). The repression-sensitization dimension in re- lation to impending painful stimulation. Journal of Consulting and Clinical Psychology, 40, 377-382.

SCHILL, T. R. (1966). Effects of approval motivation and varying conditions of verbal reinforcement on incidental learning for faces. Psychological Reports, 19, 55-60.

Spielberger, C. D., Gorsuch, R. L., \& Lushene, R. E. (1970). Manual for the State-Trait Anxiety Inventory. Palo Alto, CA: Consulting Psychologists Press.

WITKIN, H. S., \& GoodenOugh, D. R. (1977). Field dependence and interpersonal behavior. Psychological Bulletin, 84, 661-689.

YERKES, R. M., \& DoDSON, J. D. (1908). The relation of strength of stimulus to rapidity of habit formation. Journal of Comparative and Neurological Psychology, 18, 459-482.

YIN, R. (1969). Looking at upside-down faces. Journal of Experimental Psychology, 81, 141-145.

(Manuscript received for publication July 16, 1984.) 